\title{
Department of social pedagogy: an effective model of successful practice in the field of child support
}

\author{
Elena Baier $^{1, *}$, Nikolai Kurianov ${ }^{1}$ \\ ${ }^{1}$ Don State Technical University, Russia
}

\begin{abstract}
Social pedagogy in the context of the practice-oriented approach has not yet received its full validation in the system of professional training of teachers in the field of protecting children's rights. Why did it become necessary to develop a system of continuing education for teachers in children welfare? As practice shows, there has been an urgent need for teachers with knowledge and experience in the field of protecting the rights of children in the education system in the last decade, such as: a guardianship and custodianship specialist in the municipal education system; a secretary of the commission for minors' affairs and the protection of their rights in the administration of municipalities, a social teacher for working with the family in a comprehensive school, an educator for orphans (an orphanage, a boarding school, a centre for helping children, a special school and others), an adoption specialist or a foster parent support specialist, a teacher for working with deviant and delinquent children by means of physical culture and sports in the system of secondary vocational education and others. It is vitally important nowadays to train a specialist who is able to think globally and act locally, that is, who is able to solve state problems at the local level and has the required professional competencies.
\end{abstract}

\section{Introduction}

The rate of socio-economic development of the Russian Federation, the preservation and strengthening of the well-being of the country's population directly depend on the qualifications of specialists who provide state support for families and children. In the realities of the modern social situation, the issue of providing socially oriented organizations with highly qualified personnel is acute $[1,2,3]$. Hence - the special expectations and requirements of society to the system of vocational education and training of teachers. Social pedagogy in the context of the practice-oriented approach has not yet received its full validation in the system of professional training of teachers in the field of protecting children's rights [4]. Why did it become necessary to develop a system of continuing training for teachers in the field of children welfare?

The first reason is that today not a single Russian university provides teacher training programs in the context of children well-being and protection, we mean Bachelor's, Master's and $\mathrm{PhD}$ educational programs. In this connection it is worth mentioning some positive

${ }^{*}$ Corresponding author: elenabaier@list.ru 
foreign practices in this area: "Social pedagogy, a strong professional tradition in Denmark and an emerging profession in the UK, takes an approach that responds to the individual's experience of the immediate situation, seeks to nurture relational opportunities and to empower people to fully participate in their lives and society. A social pedagogically informed programme has been developed in London that uses a clear ethical stance and key theories as its foundation, and upon which structures have been developed, but no manual" [5].

On the other hand, as practice shows, there has been a high level of demand for teachers with knowledge and experience in the field of protecting the rights of children in the education system in the last decade, such as: a guardianship and custodianship specialist in the municipal education system; a secretary of the commission for minors' affairs and the protection of their rights in the administration of municipalities, a social teacher for working with families in comprehensive schools, an educator for orphans (an orphanage, a boarding school, a centre for helping children, a special school and others), an adoption specialist, a foster family support specialist, a teacher for working with deviant and delinquent children by means of physical culture and sports in the system of secondary education and others [6]. Taking into consideration the urgent need for the above-listed specialists, we have included the relevant academic subjects in the curriculum of the Social Pedagogy Department of the Don State Technical University for the 2020-2021 academic year.

The second reason was that during the opening of the department, we identified a high social need for teaching staff with research experience in the higher education system concerning family, childhood, motherhood and paternity. Therefore, while developing curricula and work programs for these academic subjects, we thought about how to attract young specialists from among teachers to the university system who are ready to continue their education in postgraduate and doctoral studies, preferably those who already have experience in the child welfare system. As a rule, these are teachers-innovators, teachersresearchers who have a desire to improve the system of protecting the rights of children. An effectively developed model will allow us to gradually and systematically replenish the faculty and staff of social institutions for the protection of children's rights.

We hope that the system of lifelong teacher training in the field of child support based on the practice-oriented approach that was developed by us at the Department of Social Pedagogy will allow us to reach a fundamentally new level of solutions to the issues of training teachers specialized in family assistance, childhood protection, motherhood and fatherhood who are actually in demand with society $[7,8,9]$.

The Russian state today sets the task for the relevant executive authorities and universities to focus on world standards [10], to correlate the quality of student training with the best practices and technologies of pedagogical education [11]. The competitiveness of the Russian economy directly depends on the qualifications of specialists providing innovative development. This explains the special expectations and requirements that society places on the vocational education and training [12].

We consider the opening of joint university departments on the basis of state social organizations, which will allow young specialists to practice their social care skills at the stage of acquiring new knowledge, to be one of the important steps in teacher training of highly qualified personnel in the sphere of state support for families and children.

The purpose of such joint university departments is to develop a system of continuous training for teachers in the field of children welfare based on strengthening the practical educational approach at the Faculty of Psychology, Pedagogy and Defectology of the Don State Technical University (DSTU). This approach will allow to provide targeted teacher training of highly qualified specialists in child welfare and protection with the help of professional educational programs that correspond to and are focused on meeting the personnel needs of the region or district. 
To achieve this goal, the joint university department is meant to solve the following main tasks:

- giving innovative classes on topical problems of social pedagogy and psychology by leading highly qualified practitioners in the relevant fields;

- systematic work with university applicants on vocational guidance involving solving specific pedagogical problems [13];

- equipping educational and joint scientific laboratories according to the academic profile of the organization to carry out scientific research, ensure the educational process and involve students in scientific work. There are no exemplary programs for a practice-oriented approach to training teachers in child rights protection in the conditions of the joint university department [14].

It is generally accepted that any conceptual model requires its own experimental validation in the form of reproduction in a real educational process. However, the conditions of upbringing and education at various levels of additional and vocational education, the peculiarities of orphans and the resource provision of a particular social service of state support for childhood, as well as the specifics of the sociocultural environment, require certain adjustments to be made in implementing a theoretically grounded model in practice.

The general integrated goal of the experimental work or pilot testing of the research was to test and approve of the conceptual model of lifelong education of teachers in the field of child protection based on the actualization of the pedagogical potential of the practiceoriented environment with given didactic tasks and conditions for constructing its contenttechnological, socio-communicative and spatial-subject components.

The experimental work consisted of two phases:

- the ascertaining phase aimed at identifying external (modality of the practice-oriented environment, program content, nature of interaction between education agents and educational technical support) and internal (social needs, motives, activities, competences or set of skills) conditions for creating a favourable personal lifestyle of orphans;

- the formative phase " $A$ " focused on constructing and enriching the pedagogical practice environment that contributes to developing university students' professional competence with given conditions and opportunities; and the formative phase "B" focused on training intending teachers in protecting the rights of childhood for constructive interaction in education.

The objectives of the ascertaining phase of the experiment were:

- to design pedagogical tools for studying the environment of pedagogical practice that contributes to developing students' professional competence;

- to analyse the content of work programs based on the practice-oriented approach to teacher training in protecting children's rights;

- to identify and define the modality of the practice-oriented environment and the state of its spatial-subject, content-technological and social components;

- to determine the interaction style of teachers in children welfare.

Let us dwell in more detail on the solution of the first two problems, since we turned to the results of studying the practice-oriented environment and the characteristics of its agents during the presentation of the material in the first part of this article.

When identifying the features of developing students' professional competence, we additionally needed to select diagnostic tools to assess the indicators of a resilient personality of future teachers involved in protecting the rights of childhood that reflect the level of their professional development. According to the model characteristics of the resilient personality by E.A. Baier [15], it is desirable to conduct a holistic study of the individual and personal characteristics of students at four levels: a pedagogical component (values, communicative level, education), a psychological component (motivation, behaviour, volition), a physical component (health group, physical development, fitness), a social component (personal self- 
realization of students, students' readiness to enter the university and self-realization in the university environment). Meanwhile, the data of all the components are timely determined by the level of forcing each of them separately. Personal development, as practice shows, is especially necessary for teachers protecting children's rights, since the fate of the family and each child individually depends on their moral and volitional core. Since our teachers involved in childhood protection and welfare services are obliged to solve various problems related to the problem of family, childhood, motherhood and fatherhood. That is why the personal qualities of resilience and the successful practical application of this model in the system of lifelong education of teachers based on the practice-oriented approach, figuratively speaking, get "wound" on the moral-volitional core based on students" full involving in activities related to state childhood support services [16, 17, 18].

Anyway, we understand that the experimental substantiation of the system of lifelong education for teachers involved in child rights protection based on actualized pedagogical potential begins with a practice-oriented (educational) environment.

Therefore, the relevance of our first study is due to the fact that students and teachers successfully cope with the academic part of their education, but experience some difficulties in the variable learning process.

The purpose of our research was to build and enrich the environment of pedagogical practice which contributes to developing students' professional competence.

\section{Materials and Methods}

During the 2019-2020 academic year a preliminary experiment was carried out at the joint university department.

At the formative "A" phase of the experiment (2019) we created the same number of (10 girls and 10 boys) two control groups (CG) and two experimental groups (EG) of third-year students of vocational colleges (CG-1 - Don State Pedagogical College, EG-1 - Don State Humanitarian College) and universities (CG-2 - Southern Federal University, EG-2 - Don State Technical University), approximately equal at the beginning of training in terms of their teaching competence. The technological practice was organized within a year in order to study its effectiveness with different accents in building a favourable research environment for the study of modern scientific knowledge and technologies in educational organisations.

\section{Results}

The control groups were engaged in the traditional research mode based on the existing teaching practice programs, while the experimental groups studied on the basis of the author's approach according to an individually developed plan of technological practice in the conditions of the joint university department.

The total amount of academic hours allocated for compulsory classes in the course "Technological practice (design and technological practice)" in the academic year in all the control and experimental groups, met the general requirements and was the same: 36 days, 216 academic hours $\left(3^{\text {rd }}\right.$ year, Term 5$)$.

The EG-1 and EG-2 were organically built in heterogeneous microenvironments of different classes - visiting orphans who are inpatients at the State Psychoneurological Dispensary (Peshkovo, Azov district, Rostov region, Russia); conversations with the attending psychiatrist and other specialists; participation in juvenile commission meetings concerning problematic issues of blood and foster "risk group" families; visiting a correctional school of type VII, in which children with disabilities and with mental retardation are trained; analysing the work of psychologists and school social worker in 
orphan asylums, secondary schools, orphanages for disabled children. Finally, a seminar based on the results of the practice was held. The theme of the seminar was: "Specific aspects of working with children with disabilities before entering school". The purpose of the seminar was to analyze the educational and correctional programs implemented in educational organisations.

It was obligatory for the students to attend classes of educational psychologists; to analyze the available methodological and research materials referring to pedagogical and psychological sciences in the form of dissertations and abstracts including more than 50 titles of different formats; to analyze the long-term and current plans and reports of the teacher psychologist.

During the teaching practice the students of the EG-1 and EG-2 worked out lesson plans of individual and group lessons, conducted lessons in different age groups in collaboration with the teacher-psychologist, that enabled the students to get involved in an open, coherent, complex, heterogeneous, flexible integrative-dynamic research activity.

\section{Discussion}

This approach allowed the students to organically integrate a heterogeneous microenvironment of varied modality. In the training sessions, the students did not only do psychological and pedagogical tasks, but also applied the personality-oriented approach to each child including the study of the child's fate reflected in the personal file, visual acquaintance with close relatives, conversations, questionnaires, etc. In addition, the students interpreted and systematized the diagnostic study of each pupil of the Centre for Helping Children using different methods, and also studied the parents (guardians) and children from foster families.

Besides, the technological practice for CG-1 and CG-2 students was also updated by forming a microenvironment which contributed to the enrichment and implementation of its pedagogical potential.

Moreover, the enrichment of the pedagogical potential of the EG-1 was realized mainly through the content and functioning methods of the spatial-subject and content-technological components, and in the EG-2 additional special attention was paid to the constructive interaction of the education agents.

\section{Conclusions}

The analysis of the teaching practice program showed that the semantic dominants uniting interdisciplinary knowledge and experience in training teachers for the protection of children's rights are the following: the human-creative essence in education, the integrative nature of education, which are revealed in the content of the program through sociocultural, psychological, pedagogical and educational foundations of the system of continuous teacher training in children protection and support.

When building and enriching the educational environment at the joint university department, we relied on the following algorithm:

- to study the typical needs and interests of the education agents and their individual and personal characteristics with the help of the students; to study the real modality of the educational environment and the possibilities of resource support of the joint university department;

- to construct an educational environment according to the developed projects, to regulate the links between practices and relations between their components (organizations, institutions, families, etc.); 
- to determine the effectiveness of updating the pedagogical potential of the educational environment of the joint university department based on studying the dynamics of students' personal development indicators and on the results obtained; to make the necessary adjustments to its content.

\section{References}

1. C. Leeson, Child \& Family Social Work 12(3), 268-277 (2007) DOI: 10.1111/j.13652206.2007.00499.x

2. S. Rogowski, Practice 23(3), 157-167 (2011) DOI: 10.1080/09503153.2011.569970

3. P.B. Smith, M.H. Bond, C. Kagitcibasi, Understanding social psychology across cultures (Sage Publications, London, 2006)

4. J. Thoburn, Journal of Children's Services 5(1), 9-24 (2010) DOI: $10.5042 /$ jcs.2010.0114

5. L.J. Harbo, R. Kemp, International Journal of Social Pedagogy 9(1), 12 (2020) DOI: 10.14324/111.444.ijsp.2020.v9.x.012

6. S. Timor-Shlevin, M. Krumer-Nevo, Health \& Social Care in the Community 24(5), 576-586 (2016) DOI: 10.1111/hsc.12227

7. A. Doucet, Do Men Mother? Fatherhood, Care and Domestic Responsibility (University of Toronto Press, Toronto, 2006)

8. A. Wolde, Väter im Aufbruch. Deutungsmuster von Väterlichkeit und Männlichkeit im Kontext von Väterinitiativen (VS Verlag für Sozialwissenschaften, Wiesbaden, 2007)

9. J. Berrick, J. Dickens, T. Pösö, M. Skivenes, Child Abuse \& Neglect 49, 128-141 (2015) DOI: $10.1016 /$ j.chiabu.2015.07.001

10. Resolution on: Adoption of the EI/UNESCO Global Framework of Professional Teaching Standards https://www.ei-ie.org/en/detail/16440/resolution-on-adoption-ofthe-eiunesco-global-framework-of-professional-teaching-standards

11. M. Payne, Journal of Social Work 2(3), 269-292 (2002) DOI: $10.1177 / 146801730200200302$

12. M.V. Zaluzhnaya, N.A. Kuryanov, A.I. Grishina, Modern Problems of Science and Education 1 (2020) DOI: 10.17513/spno.29546

13. K. Tisdall, International perspectives and empirical findings on child participation, 381-404 (Oxford University Press, 2015)

14. M.V. Zaluzhnaya, E.A. Bayer, The conference proceedings: Topical issues of social pedagogy and psychology: theory and practice (Publishing house "Sreda", Cheboksary, 2019) DOI: $10.31483 / \mathrm{a}-89$

15. E.A. Bayer, S. Avakov, N.A. Grigoryan, R.L. Arutyunyan, SHS Web of Conferences, The conference proceedings: Trends in the development of psycho-pedagogical education in the conditions of transitional society 70, 01003 (Don State Technical University, Rostov-on-Don, 2019) DOI: 10.1051/shsconf/20197001003

16. C. Bisman, British Journal of Social Work 34(1), 109-123 (2004)

17. J. Koprowska, Communication and Interpersonal Skills in Social Work (Exeter: Learning Matters, London, 2010)

18. J. Korpinen, T. Pösö, Journal of Social Work (2020) DOI: 10.1177/1468017320940635 